\title{
Long-term treatment with pegvisomant: observations from 2090 acromegaly patients in ACROSTUDY
}

\author{
Michael Buchfelder ${ }^{1}$, Aart-Jan van der Lely², Beverly M K Biller ${ }^{3}$, Susan M Webb ${ }^{4}$, Thierry Brue ${ }^{5}$, \\ Christian J Strasburger6, Ezio Ghigo7, Cecilia Camacho-Hubner ${ }^{8}$, Kaijie Pan $^{9}$, Joanne Lavenberg ${ }^{9}$, \\ Peter Jönsson ${ }^{10}$ and Juliana H Hey-Hadavi ${ }^{8}$
}

${ }^{1}$ Department of Neurosurgery, University of Erlangen-Nürnberg, Erlangen, Germany, ${ }^{2}$ Department of Medicine, Erasmus University MC, Rotterdam, the Netherlands, ${ }^{3}$ Neuroendocrine Unit, Massachusetts General Hospital, Boston, Massachusetts, USA, ${ }^{4}$ Endocrinologia (Malalties de la Hipòfisi), Hospital Sant Pau, Universitat Autònoma de Barcelona (UAB), Barcelona, Spain, ${ }^{5}$ Department of Endocrinology, Centre de Référence des Maladies Rares d'Origine Hypophysaire, Hôpital de la Conception, Marseille, France, ${ }^{6}$ Department of Medicine for Endocrinology, Diabetes and Nutritional Medicine, Charité Universitätsmedizin, Campus Mitte, Berlin, Germany, ${ }^{7}$ University Hospital Città Salute e Scienza, Turin, Italy, ${ }^{8}$ Endocrine Care Global Medical Affairs, Pfizer Inc., New York City, New York, USA, ${ }^{9}$ Endocrine Care Global Clinical Affairs, Pfizer Inc., Collegeville, Pennsylvania, USA, and ${ }^{10}$ Endocrine Care, Pfizer Health AB, Sollentuna, Sweden

Correspondence should be addressed to M Buchfelder Email

Michael.Buchfelder@ uk-erlangen.de

\begin{abstract}
Objectives: ACROSTUDY is an international, non-interventional study of acromegaly patients treated with pegvisomant (PEGV), a growth hormone receptor antagonist and has been conducted since 2004 in 15 countries to study the long-term safety and efficacy of PEGV. This report comprises the second interim analysis of 2090 patients as of May 12, 2016.

Methods: Descriptive analyses of safety, pituitary imaging and outcomes on PEGV treatment up to 12 years were performed.

Results: Prior to starting PEGV, $96 \%$ of patients had reported surgery, radiation, medical therapy or any combinations of those. At start of PEGV, $89 \%$ of patients had IGFI levels above the upper limit of normal (ULN). The percentage of patients with normal IGFI levels increased from $53 \%$ at year 1 to $73 \%$ at year 10 , and the average daily dose of PEGV increased from $12.8 \mathrm{mg}$ (year 1) to $18.9 \mathrm{mg}$ (year 10). A total of 4832 adverse events (AEs) were reported in 1137 patients $(54.4 \%)$, of which 570 were considered treatment related in 337 patients (16.1\%). Serious AEs were reported in $22 \%$ of patients, of which $2.3 \%$ were considered treatment related. Locally reported MRIs showed most patients $(72.2 \%)$ had no change in tumor size relative to the prior scan; $16.8 \%$ had a decrease, $6.8 \%$ an increase and $4.3 \%$ both. In patients with normal liver tests at PEGV start, an ALT or AST elevation of $>3 \times$ ULN at any time point during their follow-up was reported in $3 \%$.

Conclusions: This second interim analysis confirms that long-term use of PEGV is an effective and safe treatment in patients with acromegaly.

\section{Introduction}

Acromegaly is a rare disease caused by hypersecretion of growth hormone $(\mathrm{GH})$ and insulin-like growth factor I (IGFI) due to a GH-secreting pituitary adenoma (1).
Pegvisomant (PEGV) is a pegylated GH analog with eight amino acid substitutions in growth hormone-binding site 1 and the substitution of glycine for alanine at position 
120 , resulting in both enhanced affinity for the GH receptor and prevention of functional growth hormonereceptor signaling. PEGV acts as a GH receptor antagonist (2). It has been available for the medical treatment of acromegaly for more than 15 years. The initial pivotal studies included approximately 200 patients with acromegaly and demonstrated that PEGV was effective in relief of symptoms and normalization of IGFI in up to $97 \%$ of patients $(3,4)$. Because of the unique mechanism of action as a GH receptor antagonist, there was a need to collect additional data outside of the clinical trial program to better understand the safety and efficacy profile of PEGV in acromegaly patients. ACROSTUDY was developed to provide these long-term data in a real-world clinical setting.

The first real-world data on PEGV treatment came from the German Prospective Observational Study (GPOS), initiated in 2003, which reported data from over 300 patients $(5,6)$. It provided valuable clinical information and contributed to the development of the global ACROSTUDY $(5,6,7)$. Most patients from GPOS have been included into ACROSTUDY and have added to the long-term follow-up data.

ACROSTUDY was initiated in 2004 to serve as an international, post-authorization, safety surveillance study and was open to all patients with acromegaly treated with PEGV. The main study objective was to monitor the long-term safety and outcome of PEGV treatment in patients with acromegaly $(8,9,10)$. Patients were enrolled in the study on an ongoing basis and the investigators reported data from follow-up visits in electronic case report forms. The first two publications from ACROSTUDY reported on data from the study at years 4 and $5(9,10)$. In these analyses, no unexpected safety concerns were seen, but it was noted that the IGFI normalization rate was lower than that observed in the pivotal clinical trials. It was concluded that longer-term follow-up and additional patient enrolment would provide a better understanding of PEGV treatment in clinical practice $(9,10)$. The first interim analysis of this study was performed five years after the start of ACROSTUDY and included data collected on 1288 patients who were enrolled as of December 31, 2009 (11). This analysis noted low rates of increased pituitary tumor size, elevated liver enzymes and lipodystrophy. Subsequent publications of subgroups in ACROSTUDY focused on PEGV use as monotherapy and most recently of PEGV in combination with somatostatin analogs and/or dopamine agonists (12, 13). In addition, the availability of data from countries that contributed larger patient cohorts has resulted in several country-specific publications from France, Italy and Spain $(14,15,16)$.

This report comprises the second interim analysis on all patients in the main study as of May 12, 2016. It describes the results of PEGV treatment in ACROSTUDY and reports the long-term experience for up to 12 years in the patients who were part of the original cohort.

\section{Methods}

\section{Study design}

This open-label, global, observational study was conducted to monitor the long-term safety and outcomes of PEGV treatment on a large group of patients with acromegaly in a real-world clinical practice setting. Although the protocol made recommendations for the timing and type of assessments, no additional diagnostic or monitoring procedures beyond routine clinical practice were required as part of the study. Due to the observational nature of the study, PEGV dosing, frequency and titration were determined by the investigator based on clinical judgment and local practice. Descriptions of the study methods have been published previously $(8,9,10,11)$.

\section{Patients and data collection}

Patients with acromegaly treated with PEGV were enrolled on an ongoing basis after meeting all inclusion and exclusion criteria. Patients who were participating in other investigational trials for acromegaly, required surgery to decompress the tumor or non-medical therapy because of visual field loss, cranial nerve palsies or intracranial hypertension, were not eligible for enrolment. Pediatric patients $(<18$ years of age) could be included in all countries except for Italy and the United States.

Data were collected by the site investigators from the medical records at baseline; information gathered at each routine clinical visit was then added longitudinally. The parameters were captured on electronic case report forms using a Web-based tool. Baseline was defined as start of PEGV, regardless of time of enrolment into the study; as noted, some patients were already taking PEGV when they were enrolled (Fig. 1). Reported information included findings from baseline and follow-up medical history, physical exams, laboratory testing and pituitary imaging. Adverse events (AEs) were classified according to terms from the Medical Dictionary of Regulatory Activities (MedDRA) version 14.1. For serious adverse events (SAEs), the reporting period encompassed the date of informed 


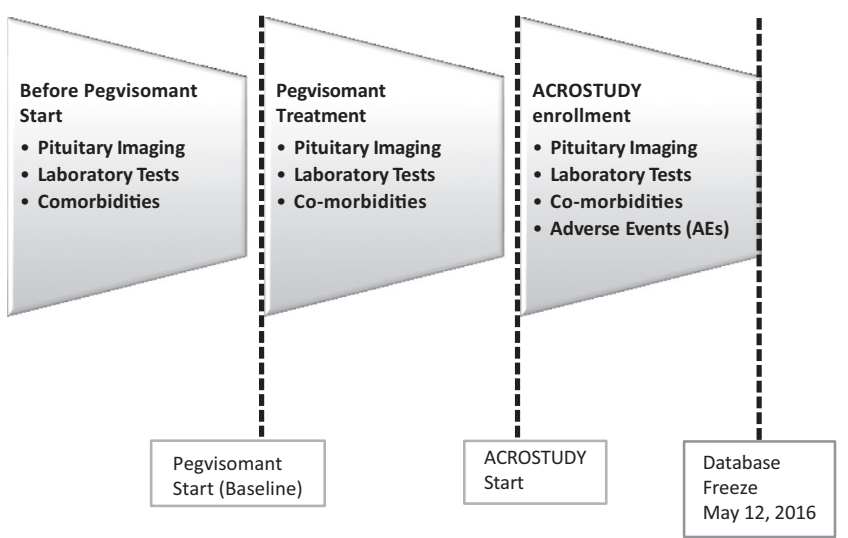

\section{Figure 1}

Data collection and flow.

consent through 28 calendar days after the last dose of PEGV. Remote and/or on-site monitoring was performed according to local policies and sites were asked to provide additional information if necessary. If local MRI reports indicated a change in pituitary tumor size (increase or decrease), the scans were to be sent for central assessment as described in a previous publication (11). The study was approved by independent local ethical committees at the investigator sites and conducted in accordance with all local legal, regulatory and ethical requirements, including informed consent signature and process prior to any data capture.

\section{Statistical methods}

There were no pre-specified statistical hypotheses tested in this study, with all data collected regarding acromegaly history and in follow-up after PEGV start to be evaluated and summarized descriptively. The full analysis set was defined as all patients who enrolled in ACROSTUDY and received at least one PEGV dose. Importantly, because baseline was defined as the start of PEGV treatment, which could be prior to enrolment into ACROSTUDY, clinical data reported at baseline were included in the analysis in order to capture as much information as possible during treatment. The following visit labels were used for data reporting: Baseline (from 6 months before to 1 day after PEGV start, except for MRI scans which allowed 1 year before and 1 day after PEGV start), month 6, month 12 and yearly visits thereafter. Categorical variables were summarized by presenting the frequency distribution and percent, which were based on the total number of patients with an observed measure of interest at a specified time point or over a specified time frame. Descriptive analyses of safety, tumor status and treatment outcomes for all patients treated with PEGV were performed. Among the patients with liver tests (AST/ALT) reported at baseline, a 'shift analysis' was performed to determine how many results shifted between normal, mildly elevated or abnormal; abnormal was defined as AST or ALT levels $>3$ times the upper limit of normal (ULN). Patients who had either AST or ALT measured at baseline and at any time during the course of PEGV treatment were included in the shift analysis.

\section{Results}

\section{Participants}

As of May 12, 2016, data from 2090 patients were available from 14 European countries and the United States (Fig. 2). Among the 2090 patients enrolled in ACROSTUDY, 466 (22.3\%) were still ongoing subjects at the time of data freeze in May 12, 2016, and 1624 (77.7\%) subjects had concluded their participation prior to this time point due to closure of study sites, exiting of study or being deceased. There were 78 (3.7\%) deaths reported. All 2090 (100\%) patients were included in the safety population for analysis of AEs including duration, severity and causality. A total of 2080 (99.5\%) patients had laboratory data recorded and 2045 patients (97.8\%) were evaluated for pituitary imaging.

\section{Patient characteristics}

Mean PEGV treatment duration was 7.6 years (median 8.1, range: 0-19.1 years). Patients were followed in

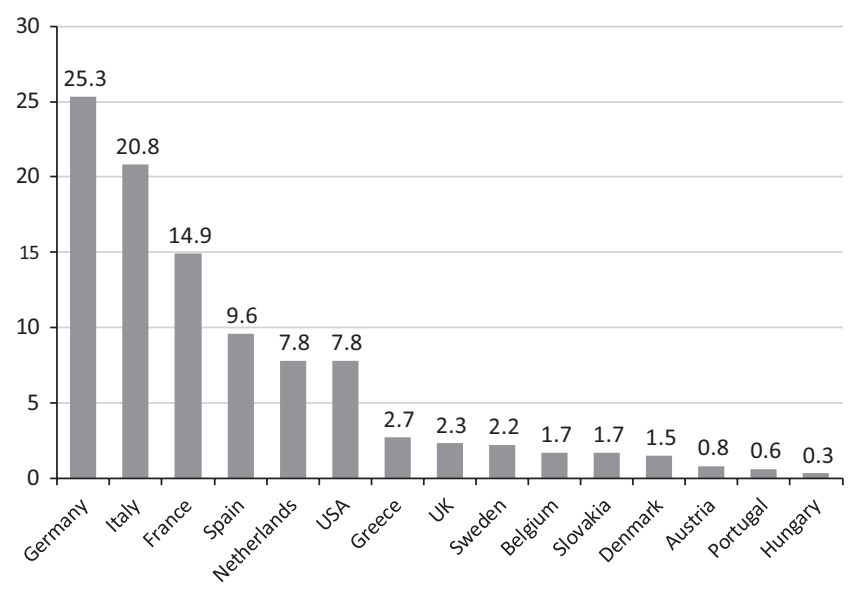

Figure 2

Country distribution (\%). 
ACROSTUDY for a mean of 6.3 years (median 6.8, range -0.1 to +12.1 years). Most patients were Caucasian (93\%) and the proportion of males and females was similar (51 vs $49 \%$ ). The mean age at diagnosis of acromegaly was 42.1 years (median 41.1, range: 1.7-83.7 years) and the mean age at the start of PEGV (baseline) was 49.5 years median 49.8, range: 3.9-85.6 years). Males were slightly younger at diagnosis (40.8 years vs 43.3 years) and were also started on PEGV at slightly younger age (48.3 years vs 50.8 years). There were 1572 patients (75\%) who started PEGV prior to enrolment into ACROSTUDY with the mean time from start of PEGV treatment to start of ACROSTUDY of 598 days (median 345.5; range -970 to +3944 days). The remaining subjects started PEGV treatment at the same time as enrolment in ACROSTUDY. Patients were grouped by age category based on the age at diagnosis of acromegaly as well as start of PEGV. There were 46 patients $(2.2 \%)$ diagnosed with acromegaly before the age of 18 years, while 15 patients $(0.7 \%)$ started PEGV before the age of 18 years. On the other side of the spectrum, there were 47 patients (2.2\%) diagnosed after age 70 years, while 166 patients (7.9\%) started PEGV after the age of 70 years.

\section{Acromegaly treatment}

Figure 3 summarizes the main treatment paradigms used in the patients prior to initiation of PEGV. Prior to starting PEGV, 96\% of patients had undergone surgery, radiation, medical therapy or any combinations of those. Among the $76 \%$ of patients who had surgery, most (96.4\%) had trans-sphenoidal surgery (TSS). Among the $26 \%$ of patients who had radiation, conventional was reported in $49 \%$ and stereotactic in $51 \%$ of cases.

After PEGV start, $8.6 \%$ of patients reported subsequent pituitary surgery (TSS in $98 \%$ of these cases). Among the $13.1 \%$ of those who were reported to have received radiation after initiation of PEGV, most (77\%) had stereotactic radiation.

\section{Co-morbidities}

Acromegaly-associated co-morbidities were captured during three time periods: before PEGV start, after the start of PEGV but before ACROSTUDY start, as well as during enrolment in ACROSTUDY (Fig. 4). In the majority of patients $(n=1827,87.4 \%)$ at least one co-morbidity was reported before starting PEGV and patients could have had more than one co-morbidity reported. Of these patients,

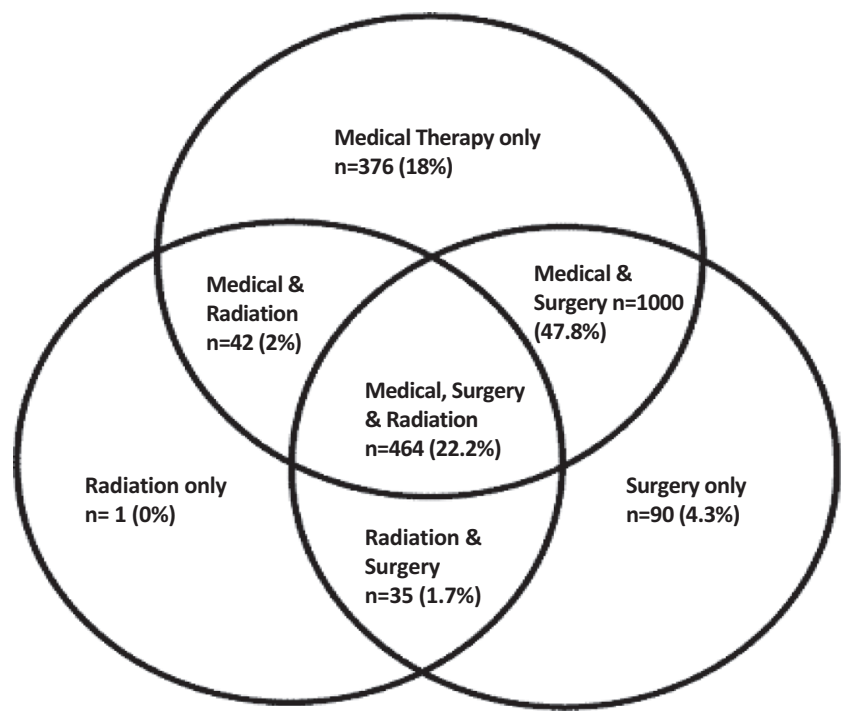

Figure 3

Treatment for acromegaly prior to initiation of PEGV.

$66 \%$ had been treated with a somatostatin analog (SSA) as the only medication prior to starting PEGV, while $31 \%$ were reported to have been treated with SSA in combination with another medication, in most cases, a dopamine agonist.

The overall percentage of patients with all co-morbidities combined and the most common co-morbidities before PEGV start, after PEGV start and before enrolment into ACROSTUDY and after

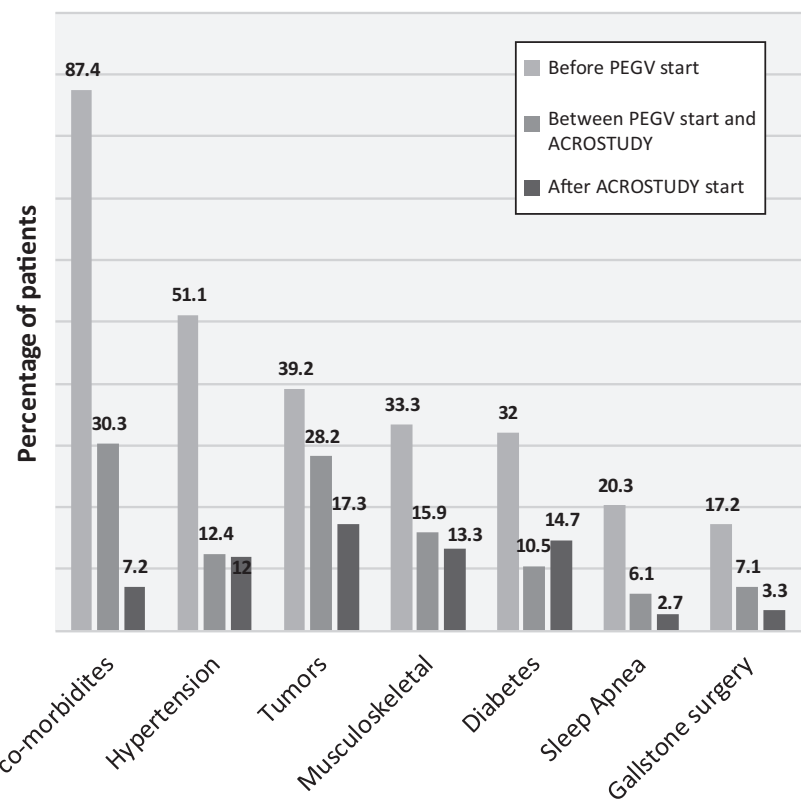

Figure 4

Most commonly reported acromegaly-related co-morbidities. 
ACROSTUDY start are shown in Fig. 4. Before PEGV start hypertension was reported in more than half of patients and diabetes in almost one-third of patients.

Included under 'Tumors' are both benign and malignant tumors at the three time periods (respectively) in thyroid $(18,7.3,6.7 \%)$, colon $(14.9,9.6,7.3 \%)$; prostate $(2.3,2.5,1.3 \%)$ and breast $(3.2,1.7,0.7 \%)$.

\section{Pituitary deficiencies}

In patients with information reported about pituitary function, deficiencies at PEGV start were most commonly observed for pituitary-gonadal function (230 of 607 patients; 37.9\%), followed by thyroid function (185 of 635 patients; 29.1\%), adrenal function (156 of 551 patients; $28.3 \%$ ) and diabetes insipidus (8 of 420 patients, $2 \%$ ). In previously irradiated patients $(n=542,26 \%)$, multiple pituitary deficiencies were common.

Most patients $(88.8 \%)$ had no genetic syndromes associated with the diagnosis of acromegaly, and such disorders were noted only in a small number of patients. Acromegaly was reported in association with an inherited syndrome in $4.9 \%$ of patients; these included multiple endocrine neoplasia (MEN type 1) (24 patients, 1.1\%), McCune Albright syndrome (20 patients, 1\%), familial acromegaly (9 patients, $0.4 \%)$ or other associated syndromes (46 patients, $2.2 \%$ ).

\section{Efficacy and safety}

At PEGV start, most $(n=1734,83 \%)$ patients were administered PEGV once daily, while the others were prescribed PEGV either once weekly $(n=180,8.6 \%)$ or between 2 and 6 times per week $(n=164,7.8 \%)$. Most patients $(n=1439,68.9 \%)$ had a starting daily dose of 10 to $<15 \mathrm{mg}$, while 57 patients $(2.7 \%)$ started at a dose $\geq 30 \mathrm{mg}$. Although daily dosing of 10 to $<15 \mathrm{mg}$ remained initially the most common, over time, doses were up-titrated. For example, at year 1, 20.6\% received 15 to $<20 \mathrm{mg}$ daily vs $7.3 \%$ at PEGV start and $18.7 \%$ received 20 to $<25 \mathrm{mg}$ vs $5.8 \%$ at PEGV start. We also observed a steady increase in the number of patients receiving $\geq 30 \mathrm{mg}$ /days from 2.7 to $20.6 \%$ at year 12 (Fig. 5). While most patients (55.5\%) received the medication as monotherapy at the start of PEGV treatment, over time that percentage decreased and combination therapy was increasingly employed as recently reported (13).

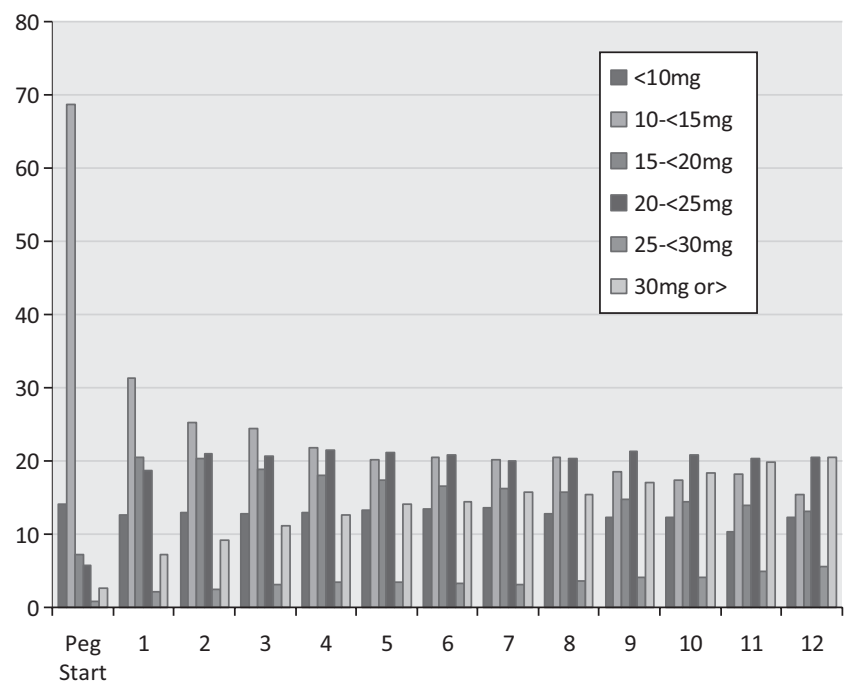

\section{Figure 5}

Pegvisomant treatment by year (daily dose).

\section{Efficacy}

At the start of PEGV, only $11 \%$ of patients had IGFI levels in the normal range. The percentage of patients with normal IGFI levels increased from 53\% at year 1 to $73 \%$ at year 10 (Fig. 6). This increased level of control was accompanied by an increase in the mean daily dose of PEGV from $12.8 \mathrm{mg}$ at year 1 to $18.9 \mathrm{mg}$ at year 10 .

\section{Safety}

A total of 4832 AEs was reported in 1137 patients (54.4\%), and the most common AE reported was 'IGFI increased' (10.5\% of patients), which was associated with the diagnosis of acromegaly. The next most

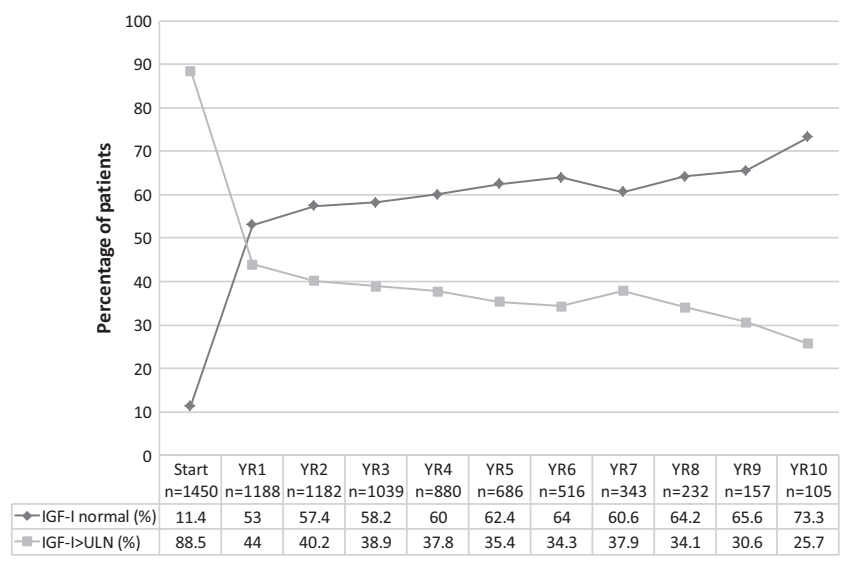

Figure 6

IGF-I normalization over time. 
commonly reported AEs were headache (4.9\%), vitamin-D deficiency (4.6\%) and arthralgia (3.7\%). In total, 570 AEs considered treatment related were experienced by 337 patients (16.1\%). Among these treatment-related AEs (in $\geq 2$ patients) were liver test elevations (transaminases increased $(n=30)$, hepatic enzyme increase $(n=18)$, ALT increase $(n=18)$, AST increase $(n=5))$, followed by gastrointestinal disorders $(n=26)$, asthenia $(n=9)$, injection site conditions (lipohypertrophy $(n=31)$, reactions $(n=16)$, erythema $(n=3)$, lipodystrophy $(n=5))$, headache $(n=7)$, fatigue $(n=6)$ and pituitary tumor recurrence $(n=9)$. SAEs were experienced in $22 \%$ of patients, of which $2.3 \%$ were considered treatment related. The most frequently reported SAEs were pituitary tumor recurrence (1\%), osteoarthritis (1\%) and death (1\%). Overall, 146 patients (7\%) were discontinued from ACROSTUDY due to SAEs, including 78 patients due to death and 24 patients discontinuing due to treatment-related SAEs. The most common cause of death was cardiovascular disorders and all deaths were considered unrelated to the treatment. Deaths occurred due to variety of reasons, most commonly cardiac disorders such as cardiac failure (5), myocardial infarction/ acute MI (4), cardiac arrest/sudden cardiac death (4). Different types of cancer were reported in eight patients. The most common SAEs resulting in discontinuation were recorded as general disorders (i.e. asthenia, adverse drug reaction, death, disease progression) and administration site conditions. The number of discontinuations due to non-serious AEs and the severity of AEs were not captured for this study.

Of the 2045 patients analyzed for pituitary imaging, 1712 patients had at least 1 local pituitary imaging result reported in follow-up after PEGV start. Reports of locally assessed MRIs showed that most patients (72.2\%) had no change in tumor size relative to the prior scan; $16.8 \%$ had decrease in tumor size, $6.8 \%$ had an increase and 4.3\% had both an increase and decrease. Changes in tumor size were reported as AEs for 90 patients (4.3\%) of which 21 (1\%) were considered treatment related. Of those listed as treatment related, eight patients $(0.4 \%)$ had study drug withdrawn. As previously reported, any pituitary MRIs showing a significant change were to be sent for centralized re-assessment (10). Among patients who had an increase as per local reading $(n=119)$, the central reading confirmed an increase in 29 patients; while in 23 patients, there was no change.

Hepatobiliary-related AEs were reported for 9.8\% of patients, of which $4.2 \%$ were considered treatment related. Drug withdrawal for this reason was reported in nine patients $(0.4 \%)$. Of the 1094 patients with normal baseline AST and ALT measurements, most (62\%), continued to have normal AST and ALT values during follow-up, while in 3\% at least one AST or ALT value $>3 \times$ ULN was reported. Of the 89 patients entering the study with a mildly elevated AST or ALT values between 1 and $3 \times$ ULN, 30 patients (34\%) shifted downward to a normal AST and ALT during follow-up on PEGV treatment, 41 (46\%) remained within their baseline measurement range, while $10 \%$ had ALT or AST $>3 \times$ ULN. Of the seven patients entering the study with an AST or ALT value 3-5× ULN, three shifted to normal, three shifted to mildly abnormal (between 1 and $3 \times$ ULN) and one patient shifted to $>5 \times$ ULN while on PEGV treatment.

Injection site reactions were reported for 71 patients (3.4\%) and the majority (65 patients, 3.1\%) were considered by the investigator to be treatment related. One case of lipohypertrophy was reported as a SAE. In an additional four patients, injection site reactions were reported as 'co-morbidities' and not as adverse event.

Despite the requirement of adequate birth control, a total of 15 pregnancies (three of which occurred in the patient's partner) were reported. The outcomes of these pregnancies included nine childbirths, three abortions and three unknown. All childbirths were reported to have resulted in a normal outcome. Data from pregnancies in ACROSTUDY have been previously reported (17).

\section{Discussion}

This observational study of treatment with PEGV in acromegaly provided an opportunity to evaluate a large 'real-world' data set $(n=2090)$ over an average of 7.6 years of PEGV treatment. Patients were treated according to local practice with no specific protocol procedures or visit dates required and laboratory tests were performed locally. Prior to starting PEGV, 96\% of subjects had undergone surgery, radiation, medical therapy or combinations of those, which in the majority (89\%) did not result in adequate IGFI control. Most patients entered ACROSTUDY after being treated with PEGV for a median duration of almost 1 year. Serum IGFI normalization rate increased over time (up to $73 \%$ in year 10). While this rate is somewhat lower than what was seen in clinical trials, it is similar to what was observed in the first interim analysis and other ACROSTUDY publications $(3,4,9,10,11,12,13,14,15$, 16). Possible explanations for the discrepancy in IGFI control between clinical trials and ACROSTUDY include the use of different criteria for IGFI normalization, absence of a dose titration scheme (as typically done in clinical 
trials), use of a variety of IGFI assays, the fact that a number of patients with an elevated IGFI were not titrated up to the maximal allowed daily dose according to the label, and that the normalization rate was assessed on a yearly basis in this database rather than at only one time point typical for the primary outcome in clinical trials. In realworld setting adherence may fluctuate and measurements of adherence were not part of this study. Therefore, normalization rate methods are not comparable to those observed in clinical trials. Tritos et al. (19) also recently proposed potential reasons for this discrepancy which included insufficient dose titration, inadequate patient adherence, possible adverse effects and economic reasons limiting dose escalations. It was also noted that over time more patients were treated with doses $\geq 30 \mathrm{mg} /$ day. In a recent analysis of ACROSTUDY looking at high-dose treatment in 56 patients, it was observed that patients who needed higher doses of PEGV have more aggressive disease (20). In ACROSTUDY, there was no indication of any 'escape' phenomenon, i.e. elevation of IGFI after initial normalization.

At the time of PEGV start $89 \%$ of patients had IGFI $>$ ULN and co-morbidities at PEGV start were common. In an analysis of the Liège Acromegaly Survey Database of 3173 patients with acromegaly, Petrossians et al. (21) described the presence of diabetes in $27.5 \%$ and hypertension in $28.8 \%$ of patients at the time of diagnosis of acromegaly. In the current study, those co-morbidities were reported higher with diabetes in 32\% and hypertension in $51 \%$ of patients at the start of PEGV. These differences could be due to the longer duration of acromegaly in an older cohort, but another possibility is that PEGV may have been more commonly prescribed in patient with metabolic co-morbidities such as diabetes and hypertension.

In subjects with normal liver tests at PEGV start, an ALT or AST elevation of $>3 \times$ ULN at any time point during their follow-up in ACROSTUDY was reported in 3\% of subjects. In nine patients $(0.4 \%)$, PEGV was withdrawn due to liver test elevations. Notably, most elevations were transient and there were no reports of liver failure. In an earlier study by Biering et al. (22), it was observed that in 12 patients with transaminases elevations during treatment with PEGV, 5 cases could be attributed to gallstones and in 4 patients transaminases normalized despite continuation of PEGV. Kasuki et al. (23) reported the experience with pegvisomant in a single Brazilian center and observed in 2 of their 27 patients ( $7.4 \%)$ mild (1.5 and $2.3 \times$ ULN) and transitory elevations of liver enzymes. In a report of Japanese patients with acromegaly, Shimatsu et al.
(24) reported ALT and AST increases in 3 (2 mild and 1 moderate) of 16 patients (16.7\%), which resolved after discontinuation of pegvisomant. The results of this analysis are consistent with observations from the initial clinical trials and prior long-term observational data $(3,8,10,11,12,13,14,15,22)$. In the current analysis of the liver test results, the majority of patients with mild elevations of ALT or AST (1-3× ULN) did not report worsening of liver tests at any time during follow-up. Monitoring of liver test during PEGV treatment should occur. However, transient elevations especially in the early months of therapy may have been missed due to the non-interventional nature of the study, the frequency of the visits and patients prone to liver test elevations may not have been treated with PEGV.

The pituitary MRI findings in this analysis were consistent with the previously reported data for ACROSTUDY $(5,9,10,11,12,13,14,15,16)$. In a retrospective analysis of 75 patients in two centers in the United Kingdom, one patient was reported to have significant tumor size increase; however, this tumor was growing prior to PEGV treatment (17). Buhk et al. (25) published the results of a German prospective study examining the long-term course of adenoma volumes during PEGV treatment by MRI. They observed tumor volume increase $>25 \%$ in 3 of 61 patients (4.9\%) during the first year of enrolment. All three patients had octreotide treatment withdrawn prior to PEGV. In ACROSTUDY, prior to PEGV initiation, $65.9 \%$ of patients were treated with SSA only, while $31.3 \%$ were treated with SSA plus another treatment (most cases dopamine agonist). Due to the observational nature of our study and timing of MRI assessments, we were not able to determine whether the pituitary volume increases predated the PEGV treatment or if they may have been temporally associated with the change of medication and reflected rebound growth after SSA withdrawal. As was previously reported (11), a limitation of the pituitary imaging assessment was that not all scans that showed a change were submitted for central reading.

ACROSTUDY provided an opportunity to evaluate long-term data in a variety of clinical settings across 15 countries. Although ACROSTUDY is maintained as a global database, certain countries have contributed more patients and data than others (Fig. 2). In a publication by Chanson et al. (14), the data of 292 French patients entered into ACROSTUDY were evaluated. They found similar findings as reported in this analysis; however, they observed a mean weight increase of $3 \mathrm{~kg}$ over 5 -year period and a significant decrease of fasting blood glucose 
over time. The previously reported Italian experience in 341 patients from 25 centers included at that time in ACROSTUDY, reported that treatment with PEGV showed high efficacy and safety similar to the global cohort (15). In Italy, PEGV is available as third-line therapy (after surgery or radiotherapy and SSA failure) and therefore in patients who had failed to normalize IGFI with these treatment modalities. Nonetheless they reported that $70.9 \%$ of patients were found to have normal IGFI levels at year 6. The publication of Spanish data from 199 patients also confirmed a favorable safety and efficacy profile and showed similar IGFI control as reported globally (16). However, PEGV dosing was lower in that report, and 52\% of the patients received combination treatment (16). In the current analysis, country-specific data were not examined separately. Differences in treatment practice, standards of care and access to medications may have influenced this analysis; the countries that contributed the majority of patients in ACROSTUDY were in Western Europe.

There are many strengths of ACROSTUDY, including large patient numbers, wide geographic representation, and a long-term patient follow-up period. Nevertheless, observational, surveillance studies like ACROSTUDY have limitations. For example, the fact that patients were enrolled into the study regardless of when they started PEGV treatment (i.e. did not need to be treatment naive) meant that many patients did not have baseline data entered before starting the medication. This was partially addressed by retrospective collection of additional relevant clinical information, such as co-morbidities from the source documents, when available. Safety data may have been missed early in treatment in those patients who had already been taking PEGV for a long time prior to enrolment in ACROSTUDY. In addition, no data about early side effects would have been obtained for patients who stopped PEGV before being considered for the study, and therefore never enrolled in ACROSTUDY. An additional limitation was possible underreporting of data regarding enrolled patients. This is because ACROSTUDY captured routine clinical care that was provided according to individual clinic/physician practice and data entry depended on the patient's visits and level of follow-up. After discontinuation of PEGV for any reason most patients also discontinued participation in ACROSTUDY. The current study did not allow us to determine patients were stopped because they did not response to PEGV treatment or to capture any possible reason for discontinuation. Finally, any bias in reporting or in patient selection (i.e. patients in which PEGV is effective) cannot be excluded.

\section{Conclusions}

ACROSTUDY provides a robust global perspective on real-world outcomes of PEGV treatment and numerous investigators $(>200)$ in 15 countries have contributed information from their clinic patients to this robust database. This second interim analysis, after more than a decade of ACROSTUDY enrolment, performed on 2090 patients, confirms that long-term use of PEGV can be an effective and safe treatment in patients with acromegaly. The low occurrence of pituitary tumor enlargement, new liver test elevations and site administration reactions was reassuring.

ACROSTUDY has provided long-term safety information that complements the safety data obtained from clinical trials. The larger numbers of subjects, including those who may not have been eligible for enrolment in clinical trials, and the longer duration of follow-up, allowed for a better understanding of overall use and the safety profile of PEGV.

\section{Declaration of interest}

ACROSTUDY Steering Committee Members: M Buchfelder, A-J van der Lely, B M K Biller, S M Webb, T Brue, C J Strasburger, E Ghigo. Pfizer Employees: C Camacho-Hubner, K Pan, J Lavenberg, J H Hey-Hadavi. P Jönssen was a Pfizer employee at the time of study completion.

\section{Funding}

This research did not receive any specific grant from any funding agency in the public, commercial or not-for-profit sector.

\section{Acknowledgements}

The authors sincerely thank all investigators, sub-investigators and study coordinators and patients for their participation and contributions to ACROSTUDY. This study has been sponsored by Pfizer Inc.

\section{References}

1 Melmed S. Medical progress: acromegaly. New England Journal of Medicine 2006355 2558-2573. (https://doi.org/10.1056/ NEJMra062453)

2 Kopchick JJ, Parkinson C, Stevens EC \& Trainer PJ. Growth hormone receptor antagonist: discovery, development, and use in patients with acromegaly. Endocrine Reviews 200223 623-646. (https://doi. org/10.1210/er.2001-0022)

3 Van der Lely AJ, Hutson RK, Trainer PJ, Besser GM, Barkan AL, Katznelson L, Klibanski A, Herman-Bonert V, Melmed S, Vance ML et al. Long-term treatment of acromegaly with pegvisomant, a growth hormone receptor antagonist. Lancet 2001358 1754-1759. (https://doi.org/10.1016/S0140-6736(01)06844-1)

4 Trainer PJ, Drake WM, Katznelson L, Freda PU, Herman-Bonert V, van der Lely AJ, Dimaraki EV, Stewart PM, Friend KE, Vance ML et al. Treatment of acromegaly with the growth hormone-receptor 
antagonist pegvisomant. New England Journal of Medicine 2000342 1171-1177. (https://doi.org/10.1056/NEJM200004203421604)

5 Schreiber I, Buchfelder M, Droste M, Forssmann K, Mann K, Saller B, Strasburger CJ \& The German Pegvisomant Investigators. Treatment of acromegaly with the GH receptor antagonist pegvisomant in clinical practice: safety and efficacy evaluation from the German Pegvisomant Observational Study. European Journal of Endocrinology 2007156 75-82. (https://doi.org/10.1530/eje.1.02312)

6 Strasburger CJ, Buchfelder M, Droste M, Mann K, Stalla GK, Saller B \& German Pegvisomant Investigators. Experience from the German pegvisomant observational study. Hormone Research 200768 70-73. (https://doi.org/10.1159/000110481)

7 Buchfelder M, Schlaffer S, Droste M, Mann K, Saller B, Brübach K, Stalla GK, Strasburger CJ \& German Pegvisomant Observational Study. The German ACROSTUDY: past and present. European Journal of Endocrinology 2009161 S3-S10. (https://doi.org/10.1530/EJE-09-0350)

8 Brue T, Castinetti F, Lundgren F, Koltowska-Häggström M, Petrossia $\mathrm{P}$ on behalf of all ACROSTUDY investigators. Which patients with acromegaly are treated with pegvisomant? An overview of methodology and baseline data in ACROSTUDY. European Journal of Endocrinology 2009161 S11-S17. (https://doi.org/10.1530/EJE-090333)

9 Brue T. ACROSTUDY: status update on 469 patients. Hormone Research 200971 (Supplement 1) 34-38. (https://doi. org/10.1159/000178035)

10 Trainer PJ. ACROSTUDY: the first 5 years. European Journal of Endocrinology 2009161 S19-S24. (https://doi.org/10.1530/EJE-090322)

11 Van der Lely AJ, Biller BMK, Brue T, Buchfelder M, Ghigo E, Gomez R, Hey-Hadavi J, Lundgren F, Rajicic N, Strasburger CJ et al. Long-term safety of pegvisomant in patients with acromegaly: comprehensive review of 1288 subjects in ACROSTUDY. Journal of Clinical Endocrinology and Metabolism 201297 1589-1597. (https:// doi.org/10.1210/jc.2011-2508)

12 Freda PU, Gordon MB, Kelepouris N, Jönsson P, KoltowskaHaggstrom $\mathrm{M} \&$ vanderLely AJ. Long-term treatment with pegvisomant as monotherapy in patients with acromegaly; experience from ACROSTUDY. Endocrine Practice 201521 264-274. (https://doi.org/10.4158/EP14330.OR)

13 Strasburger CJ, Mattson A, Wilton P, Aydin F, Hey-Hadavi J \& Biller BMK. Increasing frequency of combination medical therapy in the treatment of acromegaly with the GH receptor antagonist pegvisomant. European Journal of Endocrinology 2018178 321-329. (https://doi.org/10.1530/EJE-17-0996)

14 Chanson P, Brue T, Delemer B, Caron P, Borson-Chazot F \& Zouater H. Pegvisomant treatment in patients with acromegaly in clinical practice: the French ACROSTUDY. Annuals of Endocrinology 201576 664-670. (https://doi.org/10.1016/j.ando.2015.10.003)

15 Grottoli S, Maffei P, Bogazzi F, Cannavo S, Colao A, Ghigo E, Gomez R, Graziano E, Monterubbianese M, Jönsson P et al. ACROSTUDY: the Italian experience. Endocrine 201448 334-341. (https://doi.org/10.1007/s12020-014-0393-9)
16 Bernabeu I, Pico A, Venegas E, Aller J, Alvarez-Escola C, GarciaArnes JA, Marazuela M, Jonsson P, Mir N, Garcia Vargas M \& Spanish ACROSTUDY Group. Safety of long-term treatment with pegvisomant; analysis of Spanish patients included in global ACROSTUDY. Pituitary 201619 127-137. (https://doi.org/10.1007/ s11102-015-0691-0)

17 Van der Lely AJ, Roy Gomez R, Heissler JF, Åkerblad AC, Jönsson P, Camacho-Hübner C \& Kołtowska-Häggström M. Pregnancy in acromegaly patients treated with pegvisomant. Endocrine 201549 769-773. (https://doi.org/10.1007/s12020-014-0508-3)

18 Higham CE, Chung TT, Lawrence J, Drake WM \& Trainer PJ. Long-term experience of pegvisomant therapy as a treatment for acromegaly. Clinical Endocrinology 200971 86-91. (https://doi. org/10.1111/j.1365-2265.2008.03469.x)

19 Tritos NA \& Biller BMK. Pegvisomant; a growth hormone receptor antagonist used in the treatment of acromegaly. Pituitary 201720 129-135. (https://doi.org/10.1007/s11102-016-0753-y)

20 Van der Lely AJ, Jönsson P, Wilton P, Akerblad A-C, Cara J \& Ghigo E. Treatment with High dose of pegvisomant in 56 patients with acromegaly: experience from ACROSTUDY. European Journal of Endocrinology 201620 129-135. (https://doi.org/10.1530/EJE-160008)

21 Petrossians P, Daly AF, Natchev E, Maione L, Blijdorp K, SahnounFathallah M, Auriemma R, Diallo AM, Hulting A-L, Ferone D et al. Acromegaly at diagnosis in 3173 patients from the Liege Acromegaly (LAS) database. Endocrine-Related Cancer 201710 505-518. (https:// doi.org/10.1530/ERC-17-0253)

22 Biering H, Saller B, Bauditz J, Pirlich M, Rudolph B, Johne A, Buchfelder M, Mann K, Droste M, Schreiber I et al. Elevated transaminases during medical treatment of acromegaly: a review of the German pegvisomant surveillance experience and a report of a patient with histologically proven chronic mild active hepatitis. European Journal of Endocrinology $2006 \mathbf{1 5 4} 213-220$. (https://doi. org/10.1530/eje.1.02079)

23 Kasuki L, de Oliveira Machado E, Lumi Ogino L, Alves Coelho MA, Marques dos Santos Silva C, Almondi Wildember LE, Azerodo Lima CH \& Galdelha MR. Experience with pegvisomant treatment in acromegaly in a single Brazilian tertiary reference center: efficacy, safety and predictors of response. Archives of Endocrinology and Metabolism 201660 479-485. (https://doi.org/10.1590/23593997000000210)

24 Shimatsu A, Nagashima M, Hashigaki S, Ohki N \& Chihara K. Efficacy and safety or monotherapy by pegvisomant, a growth hormone receptor antagonist, in Japanese patient with acromegaly. Endocrine Journal 201663 337-347. (https://doi.org/10.1507/endocrj. EJ15-0619)

25 Buhk JH, Jung S, Psychogios MN, Goricke S, Hartz S, Schulz-Heise S, Klingebiel R, Forsting M, Bruckmann H, Döfler A et al. Tumor volume of growth hormone-secreting pituitary adenomas during treatment with pegvisomant: a prospective multicenter study. Journal of Clinical Endocrinology and Metabolism 201095 1-7. (https://doi.org/10.1210/ jc.2009-2363)

Received 20 July 2018

Revised version received 25 September 2018

Accepted 1 October 2018 